\title{
Implementasi Model Learning Cycle 5E Berbantu Media Video Pembelajaran Di Kelas Online
}

\author{
Muhammad Zul Fadli \\ UIN Sunan Ampel Surabaya \\ E-mail: Pondoktremas0@gmail.com
}

Tanggal Submitt: 04/04/2021 Tanggal diterima: 06/04/2021 Tanggal Terbit: 13/07/2021

\begin{abstract}
Abstrak: Model Learning Cycle 5E merupakan suatu model pembelajaran yang atraktif dan efisien guna meningkatkan minat dan fokus siswa. Selama pandemi Covid-19, kelas online memiliki banyak sekali tantangan, diantaranya pemahaman siswa terhadap materi pembelajaran yang sulit dicerna karna tanpa adanya tatap muka secara langsung. Guru dituntut lebih kreatif dalam mendesain pembelajaran agar tidak menjenuhkan dan membuat siswa merasa terbebani dengan tugas-tugas yang menumpuk. Penelitian ini merupakan penelitian study kasus dengan pendekatan deskriptif kualitatif yang membahas tentang implementasi model Learning Cycle $5 \mathrm{E}$ berbantu media vidio pembelajaran sebagai penunjang pemahaman siswa pada kelas online. Diharapkan dengan adanya penelitian ini menambah wawasan guru dalam mendesain pembelajarannya sesuai dengan kebutuhan siswa pada masa pandemi ini.
\end{abstract}

Kata Kunci: Model Learning Cycle 5E, Media Vidio Pembelajaran, Kelas Online.

\section{Pendahuluan}

Pendidikan adalah usaha sadar dan terencana untuk mewujudkan suasana belajar dan proses pembelajaran agar peserta didik secara aktif mengembangkan potensi dirinya untuk memiliki kekuatan spiritual keagamaan, pengendalian diri, kepribadian, kecerdasan, akhlak mulia, serta keterampilan yang diperlukan dirinya, masyarakat, bangsa, dan negara. ${ }^{1}$ Sumber daya manusia dapat terakomodir secara baik jika pendidikan di suatu negara benar-benar diperhatikan. Peran penting pendidikan adalah mempersiapkan generasi muda menjadi penerus roda kehidupan bangsa yang bermanfaat dan dapat diandalkan dikehidupan yang akan datang.

Proses pembelajaran di lembaga pendidikan banyak yang belum terlaksana dengan baik. Realitanya guru tidak mempersiapakan perangkat pembelajaran dengan semestinya. Desain pembelajaran hendaknya dirancang oleh guru sebelum pembelajaran dimulai, mulai dari strategi, model, metode, teknik dan lainnya yang sangat diperlukan dalam proses pembelajaran. Perencanaan pembelajaran yang tepat didukung dengan media yang kekinian membuat pembelajaran akan lebih efektif dan tujuan pembelajaran dapat tercapai.

Sepanjang praktek pembelajaran yang berlangsung banyak siswa yang kurang aktif dalam proses pembelajaran. Guru masih belum mampu menyampaikan materi pembelajaran yang berpusat pada siswa sehingga siswa merasa kurang terperhatikan.

${ }^{1}$ Republik Indonesia, UU No. 20 Tahun 2003 tentang Sistem Pendidikan Nasional. 
Pembelajaran yang membosankan dan kurang kondusif terjadi karena guru banyak yang mempertahankan metode ceramah sebagai andalan pada penyampaian materi dikelas, pembelajaran satu arah membuat suasana kelas kurang hidup dan terkesan sangat menjenuhkan.

Pengaruh hal tersebut sangat terasa yang menyebabkan kelas tidak aktif dan minat siswa tidak muncul sepanjang pembelajaran berlangsung. Waktu pembelajaran sangat mempengaruhi keefektifan proses pembelajaran berdasar beberapa penelitian yang dilakukan. Pollio pada penelitiannya menjelaskan bahwa siswa hanya mampu bertahan selama $40 \%$ dari waktu pembelajaran yang tersedia, sedang penelitian yang dilakukan Mc Keachie menyatakan bahwa $70 \%$ siswa masih dapat memperhatikan proses pembelajaran pada 30 menit pertama dan tersisa hanya 20\% saja pada 20 menit akhir pembelajaran. ${ }^{2}$

Ketika selama proses pembelajaran dalam kondisi pasif, maka siswa akan sulit mengembangkan kemampuan dengan baik. Dengan demikian munculah permasalahan yang terjadi pada siswa. Proses pembelajaran pasti memiliki tantangan tersindiri yang perlu menjadi bahan kajian oleh guru sebagai pendidik di kelas. Learning Cycle 5E (Engage, Explore, Explain, Elaborate dan Evaluate) menjadi jawaban dalam pembelajaran yang efektif guna menumbuhkan dan meningkatkan kecerdasan, kemandirian dan kreativitas siswa selama proses pembelajaran. MTs Pondok Tremas sudah mulai memanfaatkan model Learning Cycle 5E. Penggunaan model Learning Cycle 5E dirasa efektif dan berpengaruh meningkatkan potensi dan fokus belajar siswa.

Media sebagai salah satu sarana penunjang keefektifan pembelajaran. Tegeh mengatakan salah satu media pembelajaran pada masa ini yang paling banyak digunakan adalah vidio pembelajaran. ${ }^{3}$ Vidio pembelajaran merupakan media audio visual, Tegeh menyampaikan media audio visual merupakan media yang dinikmati indera pendengaran dan pengelihatan sebab menghasilkan bunyi dan visual. ${ }^{4}$ Model Learning Cycle $5 \mathrm{E}$ dengan media video pembelajaran dalam penelitian ini mampu memberi siswa pengalaman pembelajaran yang lebih menarik sehingga sikap sosial siswa akan bertambah. Pemilihan video yang sesuai dengan materi pembelajaran akan memudahkan guru memberi pemahaman kepada siswa apalagi dikelas online.

\section{Metode Penelitian}

Pembahasan dalam penulisan ini menggunakan pendekatan metode kualitatif dengan jenis penelitian study kasus. Data didapat dari wawancara, dokumentasi dan observasi dengan metodologi yang menghasilkan data deskriptif dari berbagai sumber yang ada. Study kasus pada penelitian kualitatif

2 Melvin L. Silberman, Strategi Pembelajaran Active Learning, (Bandung: Pustaka Insan Madani). 2009, Cet-6, hlm. 118.

${ }^{3}$ Tegeh, I Made, Media pembelajaran. (Universitas Pendidikan Ganesha), 2015. 158.

4 Tegeh, I Made, Simamora, A. H., \& Dwipayana, K. Pengembangan Media Video Pembelajaran Dengan Model Pengembangan 4D Pada Mata Pelajaran Agama Hindu. (Julnar Mimbar Ilmu), 24(2), 2019. 166. 
menempati tempat yang penting, karna akan membahas masalah yang terjadi dilapangan secara mendalam berdasar teori yang ada untuk mencari realitas dari fenomena yang terjadi. Penelitian ini dilakuakan pada siswa kelas VIII MTs Pondok Tremas Pacitan, Jawa Timur salah satu lembaga pendidikan dibawah naungan yayasan Perguruan Islam Pondok Tremas Pacitan yang memiliki 1000 siswa, jumlah siswa terbanyak MTs sekabupaten Pacitan.

\section{Pembahasan}

\section{A. Model Learning Cycle 5e}

Pada pengelolaan kelas, guna meraih pembelajaran baru yang lebih tinggi haruslah memahami konsep-konsep serta aturan sebelum pembelajaran berlangsung. Ketika pembelajaran baru akan dilaksanakan, sebelumnya informasi yang relevan hendaknya mampu diakses oleh siswa, hal itu mampu menjadi bagian dari pengalaman belajar. ketercapaian hal tersebut dapat dinyatakan dengan mampunya siswa menyampaikan informasi terdahulu sebum masuknya informasi baru untuk dibahas bersama. ${ }^{5}$

Model Learning Cycle 5E merupakan suatu alternatif untuk menciptakan suasana kelas yang aktif dan kreatif sepanjang pembelajaran. Model pembelajaran ini berpusat pada siswa dengan ranvangan pembelajaran yang terstruktur dan sistematis guna mencapai tujuan pembelajaran yang ditetapkan. Sepanjang proses pembelajaran, siswa dipaksa untuk aktif berpartisipasi mengikuti seluruh tahapan pembelajaran. Guru dapat memastikan hal tersebut dengan memperhatikan keberhasilan disetiap tahapannya.

Model Learning Cycle 5E dinilai mampu membuat aktif seluruh siswa selama pembelajaran berlangsung, disamping itu juga mampu membuat siswa mngingat kembali matei ajar yang telah dibahas pada pertemuan sebelumnya, menumbuhkan motivasi siswa, merangsang siswa untuk mampu memnemukan konsep melalui berbagai percobaan dan pembahasan serta menumbuhkan sikap berani tampil untuk berbicara menyampaiakan konsep yang ditemukan dalam diskusi pada kelompok. Model ini juga dapat digunakan pada kelas online dimana guru dapat lebih mengontrol siswa agar dapat aktif mengikuti pembelajaran.

Model Learning Cycle 5E adalah salah satu model studen centred yang memiliki serangkaian tahapan kegiatan yang didesain secara rinci dan terukur. Tahapan tersebut yakni meliputi engage, exploration, explanation, elaboration dan evaluation. Model ini semula digunakan untuk pelajaran sains biologi yang dikembangkan oleh Roger Bybee dan team Sains Curriculum Improveement pada tahun 1970-an dengan tujuan utamanya adalah menumbuhkan kemampuan dan

\footnotetext{
${ }^{5}$ Abdul Majid, Strategi Pembelajaran, (Bandung:PT Remaja Rosdakarya). 2013, Cet-1, hlm.76.
} 
kemahiran berkomunikasi oleh individu siswa sepanjang proses pembelajaran. ${ }^{6}$ Langkah-langkah pembelajaran tersebut dapat dijelaskan sebagai berikut; ${ }^{7}$

1. Melibatkan (Engage)

Tahap awal guru memberi informasi-informasi baru kepada siswa. Kegiatan bertumpu pada upaya peningkatan minat siswa dan pemahaman awal atas materi yang akan disampaikan, hal itu dapat dilakukan dengan memberi appersepsi sebelum pembelajaran dilaksanakan. Pengalaman pembelajaran yang diberikan berupa siswa diminta melakukan identifikasi masalah dengan tugas intruksional. Sepanjang tahap ini siswa berupaya mengsingkronisasikan pengalaman belajar yang terdahulu dengan pengalaman belajar yang sedang berlangsung. Metode yang digunakan dapat berupa metode diskusi kelas dan memperhatikan media pembelajaran berupa audio visual atau vidio pembelajaran.

2. Eksplorasi (Exploration)

Tahap eksplorasi maksudnya adalah dimana siswa diberi kesempatan untuk mengeksplor konsep-konsep pengetahuan yang didapat dari pengalaman belajar. Siswa dilibatkan secara penuh mengembangkan konsep yang didapat denghan melibatkan semua siswa dalam memberikan pendapatnya. Masalah yang dikaji dari bahan ajar dibahas secara langsung oleh siswa dalam pengawasan guru. Guru bertindak sebagai fasilitator dalam pembelajaran guna menyiapkan segala kebutuhan selama pembelajaran dari bahan ajar. Mengarahkan siswa untuk berdiskusi aktif sesuai dengan konsep yang didapat untuk menghasilkan suatu simpulan bersama. Pembelajara sains berbasis inkuiri (inquiry basedscience) ini digunakan untuk menunjang proses pembelajaran aktif, prakteknya adalah pemberian pertanyaan bertingkat kepada siswa.

3. Menjelaskan (Explanation)

Tahap ini siswa diajak muntuk fokus pada aspek pengalaman belajar tahap sebelumnya. Guru memberi kesempatan pada siswa untuk menjelaskan sejauh mana pemahaman atas bahan ajar yang menjadi pembahasan permasalahan. Siswa juga mengkomunikasikan hasil simpulannya pada teman sebaya dan guru dengan cara refleksi. Pada tahap ini diharap siswa mampu mengambil kesimpulan atas pengalaman belajarnya dan menjelaskan secara detail runtutan permasalahan yang dibahas.

4. Mengembangkan (Elaboration)

Tahapan ini menekankan pada pengembangan konseptual siswa serta keterampilan yang dimiliki. Siswa berkesempatan untuk bereksplorasi atas pengetahuan barunya. Siswa dapat mengembangkan konsep yang dimiliki dan mengaitkan dengan konsep yang ada sehingga terjadi hubungan pengetahuan $100-101$.

${ }^{6}$ Warsono dan Hariyanto, Pembelajaran Aktif, (Bandung: PT Remaja Rosdakarya). 2013, Cet-2, hlm.

${ }^{7}$ Warsono dan Hariyanto, Ibid. hlm. 100-102. 
baru yang dihasilkan dari pengalaman belajarnya. Siswa juga dituntut untuk berani mengeksplor hal-hal baru dari bahan ajar yang tersedia.

5. Evaluasi (Evaluation)

Tahapan akhir siswa dirahkan untuk mengakses pemahaman atas pengetahuan pembelajaran dengan bimbingan guru. Guru menilai kemampuan siswa dalam memahami konsep-konsep bahan ajar yang didiskusikan serta perolehan pemahaman dari informasi baru yang diterima sebagai pengalaman belajarnya. Assessment dan evaluasi sebaiknya berlangsung sepanjang proses pembelajaran agar diketahui kelemahan dan kekurangan pada prosesnya untuk segera diperbaiki agar mencapai tujuan yang ditetapkan. Rubik, portofolio, observasi guru dan wawancara siswa merupakan beberapa alat evaluasi yang dapat digunakan untuk mengukur tingkat keberhasilan. Karya ilmiah, junal, skema dan lainnya dapat menjadi acuan guru guna mengetahui seberapa jauh pemahaman siswa pada bahan ajar yang disampaiakan serta informasi baru yang didapat selama pembelajaran.

Uraian diatas dapat ditarik kesimpulan bahwa model Learning Cycle 5E merupakan alternatif model pembelajaran guna menciptakan keaktifan siswa dan keefektifan pembelajaran. Model ini memiliki tahapan pembelajaran terukur yakni; melibatkan, eksplorasi, menjelaskan, mengembangkan dan evaluasi. Tahapan ini merupakan model sistematis yang harus dilalui setiap tahapannya agar dapat dirasakan keberhasilannya.

\section{B. Peran Video Sebagai Media Pembelajaran}

Arsyad menyampaikan bahwa dalam proses pembelajaran duibutuhkan jembatan atau alat guna penyambung informasi antara guru dan siswa. ${ }^{8}$ Salah satu penunjang atau elemen penting dalam pembelajaran adalah media pembelajaran. Meningkatnya kualitas pembelajaran salah satunya diperoleh dari penggunaan media pembelajaran yang tepatyang membuat siswa termotivasi untuk belajar. Prinsip pemilihan media pembelajaran haruslah diperhatikan agar tujuan pembelajaran dapat tercapai. Prinsip mendasar pada pemilihan dan penggunaan media pembelajaran adalah dengan memperhatikan karakteristik materi pembelajaran dan karakteristik pengguna media pembelajaran. ${ }^{9}$

Cheppy Riyana menyatakan bahwa media vidio pembelajaran merupakan suatu media yang terdiri dari audio dan visual tentang konsep, informasi, gagasan dan lainnya guna menunjang pemahaman atas materi pembelajaran. ${ }^{10}$ Media vidio pembelajaran dapat meberikan informasi, menjelaskan konsep atau gagasan, tutorial keterampilan, mempengaruhi sikap dan lainnya. Media ini dapat memberikan contoh yang nyata sehingga siswa dapat dengan detail mengetahui

\footnotetext{
8 Arsyad, A. Media Pembelajaran. (Jakarta: PT. Raja Grafindo Persada). 2015. 90.

${ }^{9}$ Henich, R., Molenda, M., Russel, J. D., \& Smaldino, S. E. Instructional Media and Technologies For Learning (Seventh Edition). (New Jersey: Pearson Education, Inc). 2002.79.

${ }^{10}$ Cheppy Riyana. Pedoman Pengembangan Media Video. (Jakarta: P3AI UPI). 2007. 156.
} 
informasi dari materi pembelajaran yang disampaikan. Sajian informasi melalui media vidio pembelajaran dapat berbentuk dokumen yang nyata, dapat dilihat dilayar monitor atau diproyeksikan sehingga dapat dilihat gerak dan didengar suaranya.

Cheppy Riyana menjelaskan bahwa krakteristik media video pembelajaran yang dapat meningkatkan motivasi belajar dan efektivitas pembelajaran adalah kejalasan pesan, akrab dengan pemakainya, merepresentasikan materi ajar, visualisasi dengan media yang nyata serta dapat digunakan secara klasikal atau individual. ${ }^{11}$ Diantara tujuan media video digunakan sebagai penyaji informasi dengan cara yang menyenangkan, lebih menarik, jelas dan mudah dimengerti. Penyerapan informasi akan semakin banyak dan rinci dengan penggunaan indera penglihatan dan pendengaran secara bersamaan.

Menggunakan media vidio pembelajaran hendaknya memperhatikan beberapa hal, diantaranya persiapan sebeleum penggunaannya. Guru mempersiapkan diri dengan memahami pengaplikasian media vidio pembelajaran dan penguasaan materi ajar. Guru memberitahukan poin-poin penting yang harus diperhatikan sebelum siswa memperhatikan vidio pembelajaran. Siswa diminta fokus pada vidio pembelajaran yang diberikan agar maksud dan tujuan pembelajaran dapat tersampaiakan kepada siswa. Siswa sekolah dasar cenderung menyukai vidio pembelajaran anime sedang siswa sekolah menengah lebih menyukai vidio pembelajaran nyata.

Mata pelajaran sejarah kebudayaan Islam akan lebih menarik dan mudah difaham jika menggunakan media pembelajaran. Metode ceramah tanpa menggunakan media pembelajaran akan membuat siswa bosan dan jenuh sepanjang pembelajaran berlangsung. Guru akan lebih mudah dan terbantu ketika menggunakan media pembelajaran. Sejarah Kekhalifaan Dinasti Abbasiyah menjadi lebih mudah difaham siswa karna penyampaiannya yang nyata melalui media vidio pembelajaran. kelebihannya antara lain siswa dapat mengulang vidio berulang kali sesuai kebutuhannya memahami materi yang tersajikan.

\section{Implementasi Model Learning Cycle 5e Di Kelas Online}

Media vidio pembelajaran merupakan hal yang baru bagi siswa MTs Pondok Tremas. Sebelumnya siswa selalu belajar menggunakan media pembelajaran klasik yang tak lepas dari buku dan papan tulis saja. Digunakannya media vidio pembelajaran membuat siswa menjadi tertarik dan memperhatikan dengan seksama apa yang tampilkan oleh guru. Media video pembelajaran dapat

\footnotetext{
11 Ibid. 181.
} 
mempermudah guru dalam menyampaikan materi pembelajaran. ${ }^{12}$ Selain itu media vidio pembelajaran membuat siswa menjadi aktif dan tidak bosan sepanjang proses pembelajaran. Agustiningsih juga menekankan bahwa dengan media vidio pembelajaran dapat meningkatkan motivasi belajar siswa dan menunjang pemahaman siswa. ${ }^{13}$ Motivasi yang meningkat dan pemahaman yang lebih akan membuat siswa lebih aktif untuk berdiskusi membahas materi pembelajaran dan informasi yang didapat dari media vidio pembelajaran.

Implementasi model learning gycle $5 E$ berbantu media vidio pembelajaran pada kelas online dilakukan guru menggunakan aplikasi WhatsApp Group pada mata pelajaran sejarah kebudayaan Islam di kelas VIII A MTs Pondok Tremas dengan beberapa tahapan. Adapun tahapan-tahapannya sebagai berikut;

1. Engage

Pada tahap ini guru melakukan apersepsi pada siswa dan merangsang siswa untuk berdiskusi tentang materi yang akan disampaikan. Sebelum membuka link vidio pembelajaran yang telah disiapkan, siswa diberi arahan tentang materi apa yang akan dibahas dan poin penting apa yang harus dicapai. Siswa diberi waktu sesuai kebutuhan guna mengkaji vidio pembelajaran yang diberikan. ${ }^{14}$

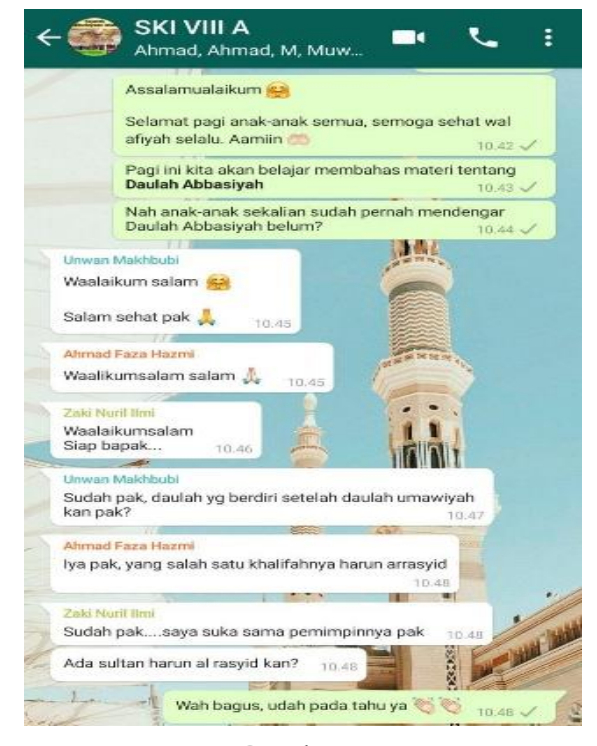

Gambar 1

Tampilan halaman aplikasi WhatsApp Group kelas VIII A MTs Pondok Tremas

Tahapan engange model learning cycle 5E diakses 21 Desember 2020.

\section{Exploration}

Tahap kedua siswa dipancing untuk melakukan diskusi berdasar informasi apa yang didapat dari vidio pembelajaran. Guru menggali sedalam-

12 Kadek, N., Dewi, R., Tastra, I. D. K., \& Pudjawan, K. Pengembangan Video Pembelajaran Berbasis Kearifan Lokal Mata Pelajaran Bahasa Bali Untun Siswa Kelas III. (E-Journal Edutech Universitas Pendidikan Ganesha Jurusan Teknologi Pendidikan), 2016. 5(2), 1-10.

${ }^{13} \mathrm{Ibid}, 13$.

14 Wawancara dengan Ustadz Ahmad Nasik Mubarok, S.Pd., Senin, 21 Desember 2020 di MTs Pondok Tremas. 
dalamnya pengetahuan siswa melalui pertanyaan-pertanyaan yang sudah disiapkan. Siswa lain diminta untuk memberikan tanggapan atas jawaban yang diberikan temannya sebagai bentuk mengeksplorasi informasi yang dimilikinya. ${ }^{15}$

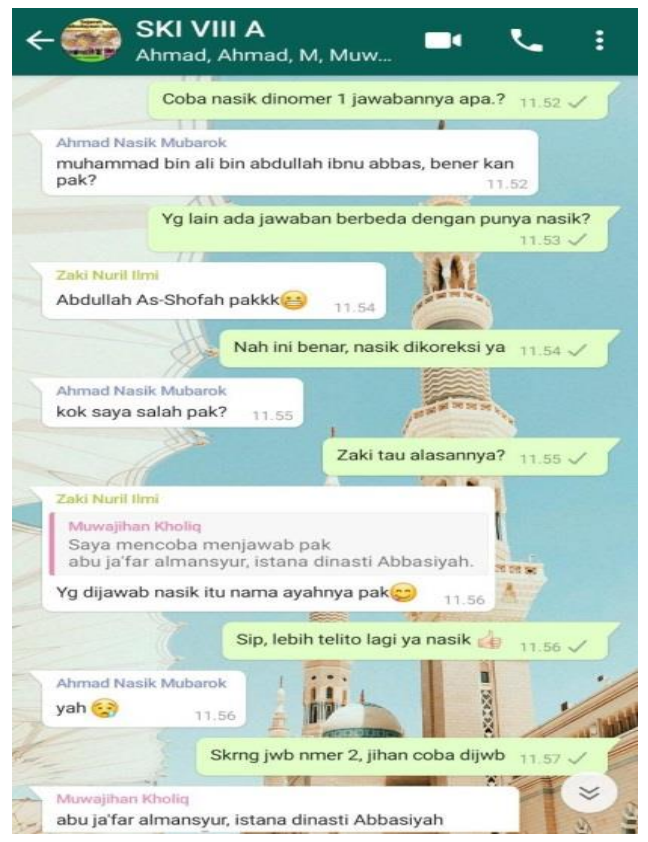

Gambar 2

Tampilan halaman aplikasi WhatsApp Group kelas VIII A MTs Pondok Tremas Tahapan exploration model learning cycle 5E diakses 21 Desember 2020.

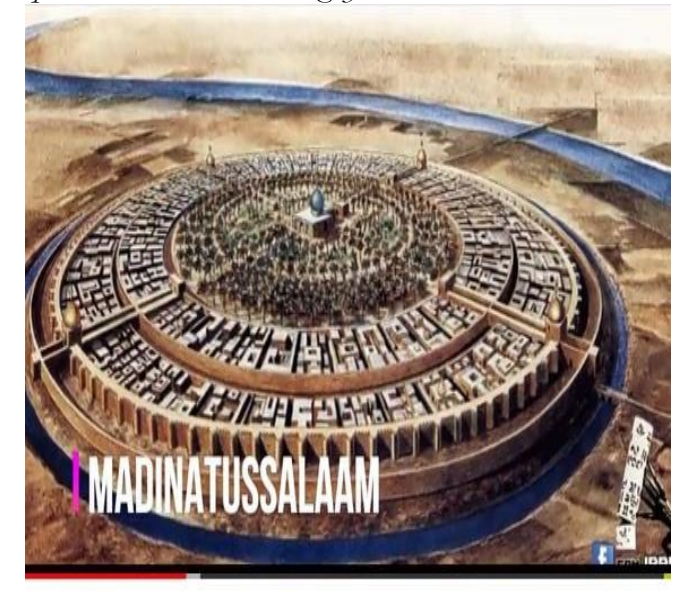

○ IAIN KEDDRI

ZAMAN KEEMASAN ISLAM - BANI ABBASIYAH

30 rb x ditonton 9 bulan lalu

Gambar 3

Tampilan media vidio pembelajaran kelas VIII A MTs Pondok Tremas link https://youtu.be/BYd6IPV9d98 diakses 21 Desember 2020.

15 Ibid. 


\section{Explanation}

Guru meminta siswa menjelaskan informasi penting yang didapatnya dari vidio pembelajaran. setiap siswa diberi waktu 3 menit oleh guru untuk presentasi menggunkan voice note agar informasi yang dijelaskan dapat tersampaikan sepenuhnya dan tidak terlalu lama mengetik pesan. ${ }^{16}$

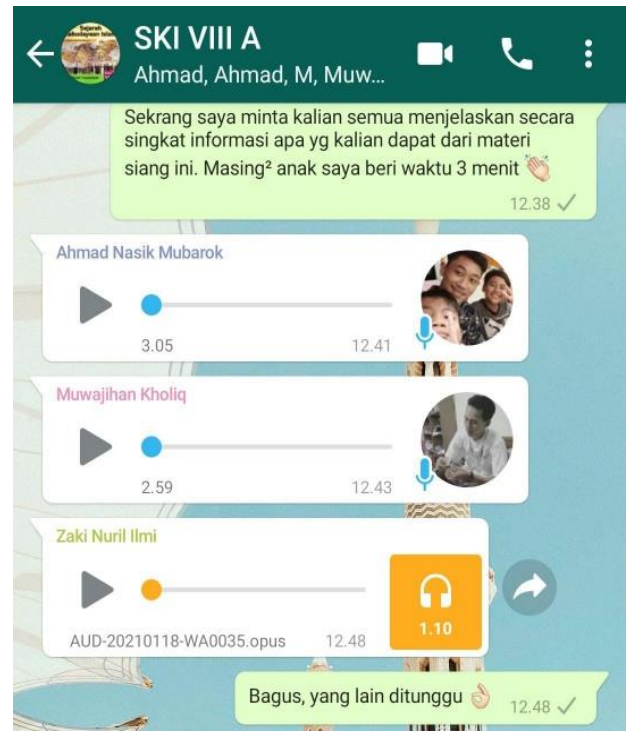

Gambar 4

Tampilan halaman aplikasi Whats App Group kelas VIII A MTs Pondok Tremas

Tahapan explanation model learning cycle 5E diakses 21 Desember 2020.

\section{Elaboration}

Siswa diminta mengembangkan informasi yang didapat setelah menonton vidio pembelajaran dengan informasi yang didapat sepanjang diskusi berlangsung. Kesimpulan dari pengebangan pengetahuan dituliskan dengan tulisan tangan yang berupa jurnal singkat dikumpulkan pada Whats App Group untuk menghindari plagiasi. ${ }^{17}$

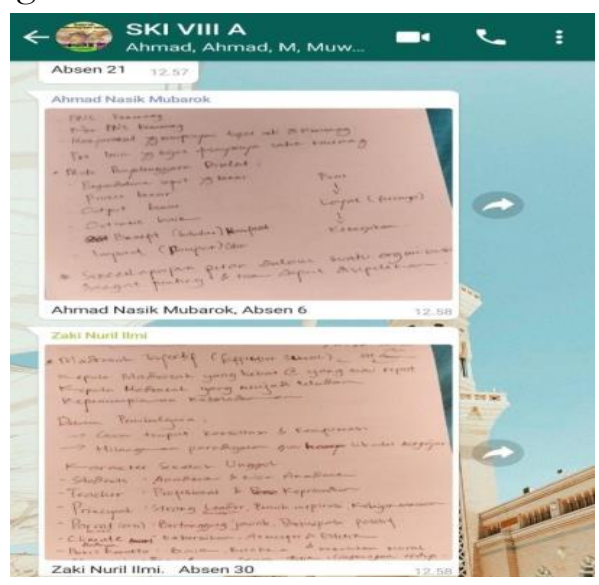

Gambar 5

Tampilan halaman aplikasi Whats App Group kelas VIII A MTs Pondok Tremas Tahapan elaboration model learning cycle 5E diakses 21 Desember 2020.

\footnotetext{
${ }^{16}$ Ibid.
}

${ }^{17}$ Ibid. 


\section{Evaluation}

Pada tahap akhir guru memberikan refleksi dan penilaian atas apa yang dikerjakan siswa mulai awal proses pembelajaran sampai dengan pengumpulan tugas harian. ${ }^{18}$

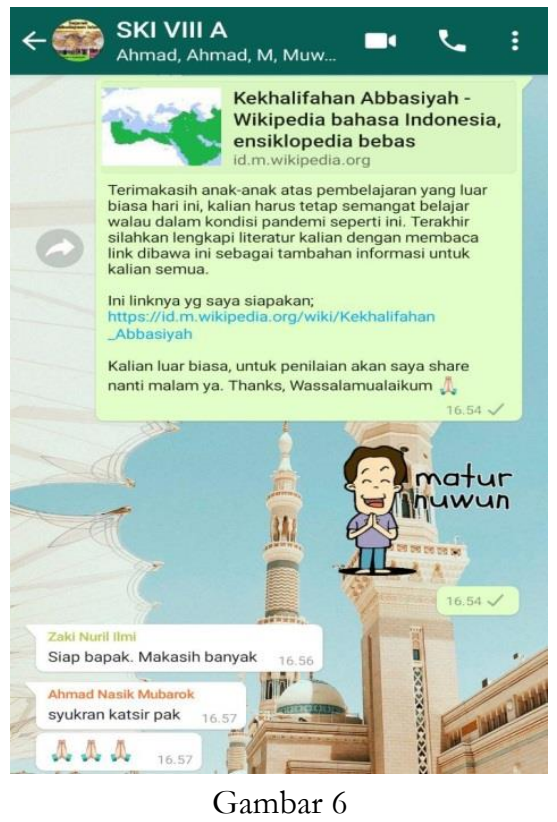

Tampilan halaman aplikasi Whats App Group kelas VIII A MTs Pondok Tremas Tahapan evaluation model learning cycle 5E diakses 21 Desember 2020.

Penelitian ini selaras dengan penelitian hasil kajian Asthira, dkk yang menjelaskan pengaruh yang signifikan pada hasil belajar IPA tampak jelas sesudah model pembelajaran learning gycle $5 \mathrm{E}$ diterapkan pada siswa. ${ }^{19}$ Menurut Setiawan, dkk pada penelitiannya mengungkapkan bahwa terjadi perbedaan mendasar pada hasil belajar sekelompok siswa yang diajarkan dengan model pembelajaran konvensional dan siswa yang diajarkan dengan model learning cycle $5 \mathrm{E}$ berbantuan mind mapping. ${ }^{20}$ Berdasar penelitian terdahulu dan pengimplementasian model learning cycle $5 \mathrm{E}$ berbantu media vidio pembelajaran pada kelas online dinilai berhasil membuat pembelajaran lebih aktif dan kreatif.

\section{Catatan Akhir}

Pembelajaran aktif membutuhkan desain yang tepat sesuai dengan kriteria atau minat siswa. Guru dituntut untuk dapat menguasai berbagai jenis model pembelajaran agar siswa tidak merasa bosan dan jenuh sepanjang pembelajaran. Model yang tepat

18 Ibid.

${ }^{19}$ W. I. Asthira, Kusmariyatni, N., \& Margunayasa, I. G. Pengarub model pembelajaran Learning Cycle " 5 e" terhadap hasil belajar IPA siswa kelas $V$ di gugus III. (E-Journal PGSD Universitas Pendidikan Ganesha), 20164(1), 1-9.

${ }^{20}$ Setiawan, I. W. P., Suartama, I. K., \& Putri, D. A. W. M. Pengarub Model Pembelajaran Learning Cycle 5 e Berbantuan Mind Mapping Terbadap Hasil Belajar Matematika. (Mimbar PGSD Undiksha), 2017, 5 (2), $1-11$. 
berbantu media pembelajaran yang tepat akan semakin menunjang keaktifan dan pemahaman siswa tentang bahan ajar yang disampaikan. Model learning cycle 5E berbantu media vidio pembelajaran mampu meningkatkan keaktifan siswa dan pemahaman pada kelas online siswa kelas VIII A MTs Pondok Tremas. Dilihat dari aplikasi WhatsApp Group yang digunakan selalu ramai dengan diskusi pertukaran informasi sebagai bentuk antusias siswa pada pembelajaran yang disampaikan guru.

\section{Daftar Rujukan}

Majid, Abdul. 2013 Strategi Pembelajaran, Bandung: PT Remaja Rosdakarya, Cet-1.

Arsyad, A., 2015. Media Pembelajaran. Jakarta: PT. Raja Grafindo Persada.

Asthira, I. W., Kusmariyatni, N., \& Margunayasa, I. G. 2016. Pengaruh model pembelajaran Learning Cycle " $5 \mathrm{e}$ " terhadap hasil belajar IPA siswa kelas V di gugus III. E-Journal PGSD Universitas Pendidikan Ganesha., 4(1).

Riyana, Cheppy. 2007. Pedoman Pengembangan Media Video. Jakarta: P3AI UPI.

Henich, R., Molenda, M., Russel, J. D., \& Smaldino, S. E. 2002. Instructional Media and Technologies For Learning (Seventh Edition). New Jersey: Pearson Education, Inc.

Kadek, N., Dewi, R., Tastra, I. D. K., \& Pudjawan, K. 2016. Pengembangan Video Pembelajaran Berbasis Kearifan Lokal Mata Pelajaran Bahasa Bali Untuu Siswa Kelas III. E-Journal Edutech Universitas Pendidikan Ganesha Jurusan Teknologi Pendidikan, 5(2).

Silberman, Melvin L. 2009. Strategi Pembelajaran Active Learning, Bandung: Pustaka Insan Madani, Cet-6.

Republik Indonesia, UU No. 20 Tahun 2003 tentang Sistem Pendidikan Nasional,.

Setiawan, I. W. P., Suartama, I. K., \& Putri, D. A. W. M. 2017. Pengaruh Model Pembelajaran Learning Cycle 5e Berbantuan Mind Mapping Terhadap Hasil Belajar Matematika. Mimbar PGSD Undiksha, 5(2).

Tegeh, I Made, 2015. Media pembelajaran. Universitas Pendidikan Ganesha.

Tegeh, I Made, Simamora, A. H., \& Dwipayana, K. 2019. Pengembangan Media Video Pembelajaran Dengan Model Pengembangan 4D Pada Mata Pelajaran Agama Hindu. Julnar Mimbar Ilmu, 24(2).

Warsono dan Hariyanto, 2013. Pembelajaran Aktif, Bandung: PT Remaja Rosdakarya, Cet-2. 